- 14,4\% bệnh nhân thiếu máu nặng; 31,7\% bệnh nhân thiếu máu vừa và $47,2 \%$ bệnh nhân thiếu máu nhẹ.

- Có mối liên quan giữa tình trang suy dinh dưỡng (ở cả 3 tiêu chí đánh giá: BMI, Albumin huyết thanh và chỉ số SGA) với thời gian lọc máu $(p<0,05)$.

\section{TÀI LIÊU THAM KHẢO}

1. Hội Tiết niệu - Thận học Việt Nam (2013), "Chẩn đoán và đánh giá thiếu máu trong bệnh thân man, Hướng dẫn điều trị thiếu máu trong bệnh thận mạn".

2. Chung S., Koh E. S., Shin S. J., Park C. W. (2012), "Malnutrition in patients with chronic kidney disease," Open J. Intern. Med., vol. 02, no. 02, pp. 89-99.

3. Ghorbani A., Hayati F., Karandish M., Sabzali S. (2020), "The prevalence of malnutrition in hemodialysis patients," J. Ren. Inj. Prev., vol. 9, no. 2, pp. e15-e15.

4. Hisham M. T. (2019), "Assessment of Malnutrition in End Stage Renal Disease Patients on Hemodialysis," J. Clin. Trials, vol. 9, no. 4, pp. 367-372.

5. Stauffer M. E. , Fan T. (2014), "Prevalence of anemia in chronic kidney disease in the United States," PLoS One, vol. 9, no. 1, pp. 2-5.

6 Wi J.' W. , Kim N.-H. (2017), "Assessment of Malnutrition of Dialysis Patients and Comparison of Nutritional Parameters of CAPD and Hemodialysis Patients," Biomed. Sci. Lett., vol. 23, no. 3, pp. 185-193.

7. Xu Y. C. , Vincent J. I. (2020), "Clinical measurement properties of malnutrition assessment tools for use with patients in hospitals: A systematic review," Nutr. J., vol. 19, no. 1, pp. 1-12.

8. Zha Y., Qian Q. (201 7), "Protein Nutrition and Malnutrition in CKD and ESRD.," Nutrients, vol. 9, no. 3.

\title{
THỰC TRANG SỬ DỤNG DỊCH VỤ CẤP CỨU Y TẾ CỦA NGƯ DẦN VEN BIỂN TẠI THÀNH PHỐ ĐÀ NẪNG
}

\section{TÓM TẮT}

Mục tiêu: mô tả thực trạng sử dụng dịch vụ cấp cứu y tế của ngư dân ven biển thànhं phố Đà Nẵng. Đối tượng và phương pháp: Nghiên cứu mô tả cắt ngang trên 480 đối tượng là ngư dân đang trú tại thành phố Đà Nẵng. Kểt quả: Tỳ lệ sử dụng dịch vụ cấp cứu y tế là $54,6 \%$, lý do cấp cứu y tế chủ yếu là tai nạn thương tích chiếm $34,4 \%$ và nguyên nhân cấp cứu do bênh lý khác chiếm 20,2\%. Có $51,7 \%$ đối tượng nghiên cứu được hỏi không có trang bị đồ dùng sơ cấp cứu tại tàu, có $48,3 \%$ có trang bị các vật tư cớ bản để sơ cẩp cứu tại tàu như bông, bằng, cồn, gạc. Kết luận: Tỷ lệ sử dụng dịch vụ cấp cứu y tế của ngư dân ven biển còn cao, do đó cần tiến hành các biện pháp can thiệp đến dịch vụ cấp cứu y tế biển đảo để giải quyết vấn đề này kịp thời.

Tư khóa: Tai nạn thương tích, cấp cứu, ngư dân.

\section{SUMMARY}

SITUATION OF USE OF MEDICAL

EMERGENCY SERVICES OF COASTAL FISHERS IN DA NANG CITY

Objective: describe the current situation of using emergency medical services of coastal fishermen in Da Nang city. Subjects and methods: A cross-sectional

${ }^{1}$ Trường Đại học Kỹ thuật $Y$ - Dược Đà Nã̃ng Chịu trách nhiệm chính: Nguyễn Khắc Minh Email: minh@dhktyduocdn.edu.vn

Ngày nhận bài: 10.5.2021

Ngày phản biện khoa học: 28.6.2021

Ngày duyệt bài: 8.7.2021
Trần Đình Trung ${ }^{1}$, Hoàng Hữu Khôi ${ }^{1}$, Nguyễn Văn Song ${ }^{1}$, Nguyễn Khắc Minh ${ }^{1}$

descriptive study on 480 fisherfolk living in Da Nang city. Results: The rate of using emergency medical services is $54.6 \%$, the main reason for medical emergency is accidents and injuries accounted for $34.4 \%$ and emergency causes due to other diseases accounted for 20.2 . \%. There are $51.7 \%$ of the research subjects surveyed not equipped with first aid equipment at the ship, $48.3 \%$ are equipped with basic supplies for first aid on the ship such as cotton, bandages, alcohol, gauze. Conclusion: The rate of using emergency medical services by coastal fishermen is still high, so it is necessary to conduct interventions to medical emergency services in order to solve this problem in a timely manner.

Keys: Accident, injury, emergency, fisherman.

\section{I. ĐẶT VẤN ĐỀ}

Nghiên cứu này được thực hiện ở các phường thuộc ven biển của thành phố Đà Nẵng nhằm tìm hiểu những vấn đề về thực trạng sử dụng dịch vụ cấp cứu, xử trí tình huống cấp cứu, thói quen sử dụng các phương tiện trong vận chuyển cấp cứu của ngư dân....nhằm phát hiện một số tồn tại để góp phần bổ sung cho chính sách cấp cứu y tế nhân dân ngày càng công bằng và hiệu quả hơn. Chính vì vậy, chúng tôi tiến hành đề tài này nhằm mục tiêu: Mô tả thực trạng sử dụng dịch vụ cấp cứu y tế của ngư dân ven biền tại thành phố Đà Nẵng.

II. ĐỐI TƯợNG VÀ PHƯƠNG PHÁP NGHIÊN CỨU

2.1. Đối tượng nghiên cứu. Ngư dân là 
những người làm nghề chài lưới, đang cư trú tại các phường thuộc khu vực biển, ven biển.

2.2. Địa điểm nghiển cứu: TP. Đà Nẵng.

2.3. Thời gian nghiên cứu: Từ tháng 4/2018 đến tháng 10/2019.

\subsection{Phương pháp nghiên cứu}

2.4.1. Thiết kế nghiên cứu: nghiên cứu mô tả cắt ngang.

2.4.2. Nội dung nghiên cứu. Mô tả thực trạng sử dụng dịch vụ cấp cứu y tế của ngư dẩn ở các phường thuộc khu vực biển, ven biển trên địa bàn thành phố.

\subsection{Cõ̃ mấu và phương pháp chọn mẫu}

2.5.1. Cõ̃ mẫu

- Áp dụng công thức ước lượng cho một tỷ lệ:

$$
n=Z_{(1-a / 2)}^{2} \frac{p(1-p)}{d^{2}}
$$

+ n: cõ̃ mẫu tối thiểu hợp lý

+ p: tỷ lệ ngư dân vùng biển sử dụng dịch vụ cấp cứu y tế tại các cơ sở y tế tham gia thực hiện cấp cứu y tế là 0,5 .

+ a: mức ý nghĩa thống kê là 0,05

+ Z: Giá trị tương ứng của hệ số tin cậy: $Z=1,96$.

+ d: Sai số cho phép 4,5\% $(d=0,045)$

Cỡ mẫu tính được là: $n=474$ đối tượng nghiên cứu. Trên thực tế, nhóm nghiên cứu chúng tôi đã tiến hành khảo sát trên 480 đối tượng nghiên cứu.

\subsubsection{Phương pháp chọn mẫu}

Chọn mẫu bằng phương pháp chọn mẫu chùm 2 giai đoạn:

Giai đoạn 1: Chọn đối tượng nghiên cứu trong 09 phường ven biển tại $\mathrm{Tp}$. Đà nắng.

Giai đoạn 2: Dựa vào khung mẫu là danh sách ngư dân tổng hợp của 09 phường, chúng tôi chọn ngẫu nhiên 480 người thuộc các phường ven biển.

2.6. Phương pháp thu thập thông tin. Sử dụng bộ câu hỏi soạn sã̃n phỏng vấn trực tiếp ngư dân để đánh giá thực trạng sử dụng dịch vụ cấp cứu y tế biển đảo của ngư dân tại các phường thuộc khu vực biển, ven biển.

2.7. Phương pháp xử lý và phân tích số liệu. Phiếu điều tra được làm sach bằng cách đọc lại, được nhập và mã hóa bằng phần mềm Epidata3.1. Sau đó được phân tích bằng phần mềm thống kê SPSS 18.0.

Phân tích thống kê mô tả, tính tần số, test Chi-Square ở mức ý nghĩa $a=0,05$ để kiểm định sự khác biệt giữa hai hay nhiều tỷ lệ.

2.8. Đạo đức trong nghiên cứu. Thông báo rõ mục đích nghiên cứu với đối tượng khảo sát, chỉ đưa vào danh sách nghiên cứu khi được sự đồng ý của họ.

Các thông tin cá nhân thu nhận được từ đối tượng khảo sát chỉ được sử dụng vào mục đích nghiên cứu khoa học. Các thông tin này được đảm bảo bí mật, chỉ được công bố khi có sự đồng ý của đối tượng nghiên cứu.

Những kết quả nghiên cứu, ý kiến đề xuất, giải pháp can thiệp được sử dụng vào mục đích nâng cao chất lượng cấp cứu y tế cho ngư dân.

2.9. Hạn chế của nghiên cứu. Đảm bảo tính đạo đức trong nghiên cứu nên sẽ có sai số chọn do đối tượng không đồng ý tham gia phỏng vấn.

Đánh giá thu nhập hộ gia đình có thể có những sai số do người cung cấp thông tin bỏ sót hoặc cố tình nói thấp hơn giá trị thực tế.

\section{KẾT QUẢ NGHIÊN CỨU}

\section{1. Đăc điểm chung của đối tượng} nghiên cứu

Bảng 3.1 Thông tin chung về đôî tượng nghiên cứu

\begin{tabular}{|c|c|c|}
\hline Thông tin chung & $\begin{array}{l}\text { Số lượng } \\
(n=480)\end{array}$ & $\begin{array}{l}\text { Tỷ lệ } \\
(\%)\end{array}$ \\
\hline Giới: & 229 & 47,7 \\
\hline Nữ & 251 & 52,3 \\
\hline Nhóm tuối: $\quad \leq 30$ & 56 & 11,7 \\
\hline Từ trên $30-40$ & 112 & 23,3 \\
\hline Từ trên $40-50$ & 126 & 26,3 \\
\hline Từ trên 50 đến $<60$ & 106 & 22,1 \\
\hline$\geq 60$ & 80 & 16,7 \\
\hline \multicolumn{3}{|l|}{ Trình độ học vấn } \\
\hline Mù chữ/tiếu học & 82 & 17,1 \\
\hline Trung học cơ sở & 157 & 32,7 \\
\hline Trung học phố thông & 139 & 29,0 \\
\hline Trung cấp/cao đằng & 46 & 9,6 \\
\hline Đai hoc/sau đai hoc & 56 & 11,7 \\
\hline \multicolumn{3}{|l|}{ Mức thu nhâp } \\
\hline Nghèo & 48 & 10,0 \\
\hline Cận nghèo & 42 & 8,8 \\
\hline Trung bình trở lên & 390 & 81,3 \\
\hline \multicolumn{3}{|l|}{ Có tham gia BHYT } \\
\hline Có & 443 & 92,3 \\
\hline Không & 37 & 7,7 \\
\hline
\end{tabular}

Nhận xét: trong số đối tượng nghiên cứu, nam chiếm tỷ lệ $47,7 \%$ và nữ chiếm tỷ lệ $52,3 \%$;

Các nhóm tuổi tương đương nhau, trong đó theo thứ tự tỷ lệ từ cao đến thấp gồm nhóm 4050 tuổi $(26,3 \%)$, nhóm 30-40 tuổi $(23,3 \%)$, nhóm $50-60$ tuổi $(22,1 \%)$, nhóm tuổi già $\geq 60$ tuổi $(16,7 \%)$, nhóm $\leq 30$ tuổi $(11,7 \%)$;

Về trình độ học vấn, chiếm tỳ lệ cao nhất là trung học cơ sở $(32,7 \%)$, tiếp theo là trung học phổ thổng $(29,0 \%)$, trình độ trung cấp/cao đẳng/đại học/sau đại học $(21,3 \%)$ và thấp nhất 
là mù chữ/tiểu học $(17,1 \%)$;

Về mức thu nhập, theo quy định chuẩn nghèo, cận nghèo tại thành phố Đà Nẵng, trong tổng số các đối tượng nghiên cứu có $10,0 \%$ là nghèo, 8,8\% là cận nghèo, còn lại là đối tượng có mức thu nhập từ trung bình trở lên $(81,3 \%)$.

Tỷ lẹ đối tượng nghiên cứu tham gia bảo hiểm y tế khá cao, chiếm 92,3\%, số đối tượng không tham gia bảo hiểm y tế chiếm tỷ lệ thấp 7,7\%.

3.2. Thực trạng về sử dụng dịch vụ cấp cứu y tế của ngư dân ven biển

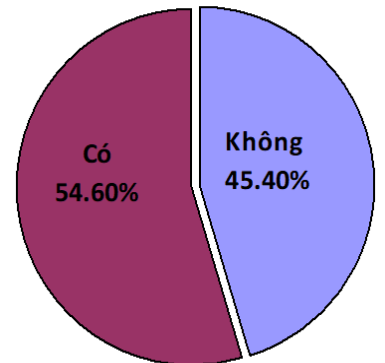

Biểu đồ 3.1. Tình trạng sử dụng dịch vụ câp cứu y tếtrong 12 tháng qua

Nhân xét: trong vòng 01 năm qua, tỷ lẹ đối tượng nghiên cứu có sử dụng dịch vụ cấp cứu y tế chiếm 54,6\%.

Bảng 3.2. Lý do sử dung dịch vụ cấp cứu y tế của ngư dân ven biển

\begin{tabular}{|c|c|c|}
\hline Lý do cấp cứu y tế & Số lượng & Tỷ lệ \\
\hline Tai nận thương tích & 165 & 34,4 \\
\hline Bệnh lý khác & 97 & 20,2 \\
\hline Không & 218 & 45,4 \\
\hline Tống cộng & $\mathbf{4 8 0}$ & $\mathbf{1 0 0 , 0}$ \\
\hline
\end{tabular}

Nhận xét: Lý do cấp cứu y tế chủ yếu là tai nạn thương tích chiếm $34,4 \%$ và nguyên nhân cẩp cứu do bệnh lý khác chiếm 20,2\%.

Bảng 3.3. Trang bị đồ dùng sơ cấp cứu (bông, băng, cồn, gạc) tại tàu của ngư dân ven biển

\begin{tabular}{|c|c|c|}
\hline $\begin{array}{c}\text { Trang bị sơ cấp } \\
\text { cứu tại tàu }\end{array}$ & $\begin{array}{c}\text { Số } \\
\text { lượng }\end{array}$ & Tỷ lệ \\
\hline Có́ & 232 & 48,3 \\
\hline Không & 248 & 51,7 \\
\hline Tống cộng & $\mathbf{4 8 0}$ & $\mathbf{1 0 0 , 0}$ \\
\hline
\end{tabular}

Nhận xét: Có $48,3 \%$ có trang bị các vật tư cơ bản để sơ cấp cứu tại tàu như bông, băng, côn, gạc.

Bảng 3.4. Biêt về số điện thoai cấp cứu $y$ tế khân cấp của ngư dân ven biển

\begin{tabular}{|c|c|c|}
\hline $\begin{array}{c}\text { Biết về số điện thoại cấp } \\
\text { cứu y tế }\end{array}$ & $\begin{array}{c}\text { Số } \\
\text { Iượng }\end{array}$ & Tỷ lệ \\
\hline Có và trá lời đúng cách gọi & 297 & 61,9 \\
\hline Có và trả lời sai & 51 & 10,6 \\
\hline Không & 132 & 27,5 \\
\hline Tống & $\mathbf{4 8 0}$ & $\mathbf{1 0 0 , 0}$ \\
\hline
\end{tabular}

Nhận xét: Tỷ lệ ngư dân biết số điện thoại cấp cứu y tế và trả lời đúng cách gọi là $61,9 \%$ (chỉ cần bấm 115); biết số nhưng cách gọi sai chiếm 10,6\% (có thêm mã vùng) và hoàn toàn không biết là $27,5 \%$.

Bảng 3.5. Sau bao lâu cán bộ y tế can thiệp câp cứu (được tính từ lúc xảy ra tình trạng cấp cứu đến khi được cán bộ y tế can thiêpp)

\begin{tabular}{|c|c|c|}
\hline $\begin{array}{c}\text { Thời gian tiếp cận } \\
\text { được cán bộ y tế }\end{array}$ & Số lượng & Tỷ lệ \\
\hline Thời gian trung bình & $14,16 \pm 7,18$ phút \\
\hline Thời gian nhanh nhất & 02 phút \\
\hline Thời gian chậm nhất & 40 phút \\
\hline
\end{tabular}

Nhận xét: Thời gian trung bình đối tượng cấp cứu được cán bộ y tế tiếp cận can thiệp sau khi xảy ra tình trạng cấp cứu là 14,16 phút, trong đó có trường hợp nhanh nhất là 2 phút và chậm nhất là 40 phút, nhóm thời gian dưới 10 phút chiếm tỷ lệ cao nhất $(45,5 \%)$.

\section{BÀN LUẬN}

4.1. Đăc điểm chung của đối tượng nghiên cứu. Trong số đối tượng nghiên cứu, nam chiếm tỷ lê $47,7 \%$ và nữ chiếm tỷ lế 52,3\%; Các nhóm tuổi tương đương nhau, trong đó theo thứ tự tỷ lệ từ cao đên thấp gồm nhóm 40-50 tuổi (26,3\%), nhóm 30-40 tuổi $(23,3 \%)$, nhóm $50-60$ tuổi $(22,1 \%)$, nhóm tuổi già $\geq 60$ tuổi $(16,7 \%)$, nhóm $\leq 30$ tuổi $(11,7 \%)$; Về trình độ học vấn, chiếm tỷ lệ cao nhất là trung hoc cơ sở $(32,7 \%)$, tiếp theo là trung hoc phổ thổng $(29,0 \%)$, trình độ trung cấp/cao đẳng/đại học/sau đại học $(21,3 \%)$ và thấp nhất là mù chữ/tiểu học $(17,1 \%)$;

Về mức thu nhập, theo quy định chuẩn nghèo, cận nghèo tại thành phố Đà Nẵng, trong tổng số các đối tượng nghiên cứu có $10,0 \%$ là nghèo, 8,8\% là cận nghèo, còn lại là đối tượng có mức thu nhập từ trung bình trở lên $(81,3 \%)$. Về nghề nghiệp, có $12,7 \%$ đối tượng nghiên cứu làm nghề lao động biển và $87,3 \%$ thuộc các ngành nghề khác.

Tỷ lệ đối tượng nghiên cứu tham gia bảo hiểm y tế khá cao, chiếm 92,3\%, số đối tượng không tham gia bảo hiểm y tế chiếm tỷ lệ thấp 7,7\%.

BHYT được coi là một trong những giải pháp nhằm đảm bảo tính công bằng trong chăm sóc, bảo vệ và nâng cao sức khoẻ của nhân dân. Hiện nay Đà Nẵng cũng như các tỉnh khác trong cả nước đều tiếp tục thực hiện Luật $B H Y T$ và chính sách hỗ trợ KCB cho người nghèo. Tính đến cuối năm 2017, tỷ lệ dân số bao phủ về BHYT toàn dân tại thành phố Đà Nẵng đạt $95,5 \%$, là một trong những tỉnh/thành phố có tỷ 
lê bao phủ cao nhất cả nước. Đây là điều kiện thuận lợi đảm bảo tính công bằng trong chăm sóc sức khoẻ.

Tai đia bàn khảo sát, tỷ lê ngư dân tham gia bảo hiểm y tế đat 92,3\%, cao hơn nghiên cứu của Trần Đăng Khoa - huyện Như Xuân, Thanh Khoa $(67 \%)$ và cao hơn tỷ lệ có thẻ BHYT của cả nước năm 2015 (86,0\%) [3].

Tiếp cận thông tin chăm sóc sức khoẻ là một yếu tố quan trọng trong việc chăm sóc, bảo vệ và nâng cao sức khoẻ của ngư dân, khi ngư dân được tiếp cận đầy đủ thông tin về các loại dịch vụ y tế được cung cấp tại địa phương sinh sống thì họ sẽ có cơ sở để ra quyết định tiếp cận và sử dụng dịch vụ y tế cho mình và cho mọi người khi ổm đau. Giảm tình trạng vượt tuyến là giảm chi phí cho KCB, giảm gánh nặng cho kinh tế của gia đình.

4.2. Thực trạng về sử dụng dịch vụ cấp cứu y tế của ngư dân ven biển. Do đó qua kết quả khảo sát chúng tôi thấy rằng, tăng cường việc đảm bảo cho mọi ngư dân được tiếp cận với thông tin về loại dịch vụ y tế trong đó có dịch vụ cấp cứu y tế là một trong những yếu tố góp phần đảm bảo cho công bằng trong tiếp cận DVYT của ngư dân cần được phát huy hơn nữa trong thời gian đến. Trong vòng 01 năm qua, tỷ lệ đối tượng nghiên cứu có sử dụng dịch vụ cấp cứu y tế chiếm $54,6 \%$. Về lý do sử dụng dịch vụ y tễ thì tỷ lệ ngư dân có tai nạn thương tích là $34,4 \%$, thấp hơn nghiên cứu của Nguyễn Văn Tâm (2016) và cộng sự ở khu vực phía Bắc cho thấy tỷ lệ TNTT của ngư dân và thuyền viên lần lướt là $41,67 \%$ và $3,68 \%$ [5], tuy nhiên nghiên cứu của chúng tôi cao hơn kết quả nghiên cứu của tác giả Lê Hông Minh (2011) tại một số tỉnh phía Nam với tỷ lế TNTT là $11,8 \%$ [4]. Tỷ lê TNTT cao nhất ở nhóm ngư dân và thuyền viên có tuổi nghề $\leq 5$ năm và $6-10$ năm, kết quả này tương đồng với nghiên cứu của tác giả Nguyễn Thị Giang và cộng sự tại Nghệ An (2016) [2].

Trong vòng 01 năm qua, tỷ lệ đối tượng nghiên cứu có tình trạng đau ốm cần cấp cứu là 20,2\%. Tai nạn thương tích hay bệnh tật là một trong những thách thức của $Y$ học nghề nghiệp đối với ngư nghiệp. Nhiều nghiên cứu đã chỉ ra rằng nguy cơ tai nạn lao động ở trên tàu dù được trang bị và có các chương trình can thiệp tốt thì rủi ro bênh tất và tai nan vẫn cao hơn 2550 lần so với lao động trên bờ [8]. Mặc dù có nhiều nghiên cứu về tỷ lệ bệnh tật và tai nạn ở ngư dân, nhưng con số khổng hề thống nhất. Nhiều nghiên cứu chỉ ra rằng tỷ lệ này phụ thuộc vào thời gian mà ngư dân làm việc trên biển, thời gian làm việc càn lớn thì tỷ lệ này càng cao. Tỷ lệ tai nạn và bệnh tật của nghiên cứu chúng tôi cao hơn các nước Châu Âu $(0,8$ trên 1000 ngư dân mỗi năm) vì các nước Châu Âu đã và đang thực hiên rất nhiêu chương trình y tế can thiệp và hỗ trợ nâng cao sức khoẻ cho ngư dân của ho [8].

Qua khảo sát $51,7 \%$ đối tượng nghiên cứu được hỏi không có trang bị đồ dùng sơ cấp cứu tại tàu, có $48,3 \%$ có trang bị các vật tư cơ bản để sơ cấp cứu tại tàu như bông, băng, cồn, gac..,trong nghiên cứu của tác giả Nguyến Văn Tâm (2021) về công tác chăm sóc sức khỏe cho ngư dân làm việc trên tàu đánh bắt hải sản đã điêu tra trên 426 chủ tàu/ thuyền trưởng cho thây tỷ lệ tàu có trang bị sơ cấp cứu là $38,73 \%$, tỷ lệ này thấp hơn nghiên cứu của chúng tôi[6]. Ngư nghiệp là một ngành nghề lớn và là một trong những nghề nghiệp nguy hiểm nhất. Thời gian làm việc dài, khắc nghiệt, máy móc nhiều nên tỷ lệ tai nạn của ngư dân rất cao. Dù ở những nước phát triển hay những nước đang phát triển thì việc cung cấp đồ dùng sơ cấp cứu cho ngư dân cũng là một vấn đề đáng quan tâm [7].

Tỷ lệ ngư dân biết số điện thoại cấp cứu y tế và trả lời đúng cách gọi là $61,9 \%$ (chỉ cần bấm 115); biết số nhưng cách gọi sai chiếm 10,6\% (có thêm mã vùng) và hoàn toàn không biết là $27,5 \%$. Thời gian trung bình đối tượng cấp cứu được cán bộ y tế tiếp cận can thiệp sau khi xảy ra tình trạng cấp cứu là 14,16 phút, trong đó có trường hợp nhanh nhất là 2 phút và chậm nhất là 40 phút, nhóm thời gian dưới 10 phút chiếm tỷ lệ cao nhất (45,5\%). Phần lớn cho rằng được cán bộ y tế hỗ trợ kịp thời trong các tình trạng cấp cứu khẩn cấp, chiếm tỷ lệ 85,5\%, tỷ lệ người dân cho rằng được cán bộ y tế hỗ trợ tuy nhiên không kịp thời là thấp $(14,5 \%)$. Trong bối cảnh kinh tế phát triển như hiện nay, nhu cầu được chăm sóc y tế của ngư dân ngày càng tăng cao, mô hình bệnh tật thay đổi, nhiều tình trạng bệnh lý đòi hỏi phải được xử trí khẩn cấp thì nhu cầu sơ cấp cứu ban đẩu, vận chuyển cấp cứu có hỗ trợ của nhân viên y tế, chẩn đoán và xử trí hiệu quả tại các Đơn vị Cấp cứu đa khoa ngày càng trở nển quan trọng. Và theo thời gian, y học cấp cứu ngày càng chứng tỏ vai trò tiên phong thông qua cách tiếp cận và giải quyết các vấn đề nóng của y học, thông qua cách tác động vào xã hội và cộng đồng, đã và đang trở thành một mũi nhọn của y học hiện đại [1].

\section{KẾT LUÂN}

Thực trạng và nhu cầu cấp cứu tai nạn 
thương tích và bệnh lý khác chiếm 54,5\%, trong đó cấp cứu y tế chủ yếu là tai nạn thương tích chiếm $34,4 \%$ và nguyên nhân cấp cứu do bệnh lý khác chiếm 20,2\%.

\section{TÀI LIÊU THAM KHẢO}

1. Hà Ânh (2017). Tiếp nhận và Theo dõi bênh nhân cấp cứu nặng. s.l. : Hội ningị Quốc tế về Y̛ học cấp cứu nắm 2017, chủ biển.

2. Nguyễn Thị Giang, Nguyễn Bích Diệp, Nguyễn Đình Khuề (2016). Thực trang tai nan lao động và môt số yếu tố liên quan của ngư dẩn đánh bắt hải sản xa bờ thị xã Cửa Lò, tỉnh Nghệ An năm 2014. s.l. : Tap chí Y học dự phòng, Tập XXVI, số 11 (184) 2016,

3. Trân Đăng Khoa (2013). Thực trạng và kết quả một số giải pháp can thiệp tăng cương tiếp cân sử dụng dịch vụ khám, chưa bệnh y tế công lập tại huyện Như Xuân 2009-2011. Thanh Hóa : Luận án Tiến sĩ Y tế Công cộng, đại học Y tế công cộng.

4. Lê Hồng Minh (2011). Ṅghiên cứu điều kiện lao động và sức khỏe nghề nghiệp của ngư dân đánh bắt hải sản xa bờ ở một sổ tỉnh phía Nam Việt Nam. Hà Nôii : Luân án tiến sĩ, Học viện Quân y.

5. Nguyến Văn Tẩm (2016). Thực trạng tai nan thương tích của ngư dân đánh bắt xa bờ và thuyền viên khu vực phía Bắc năm 2014-2016. không biết chủ biên : Kỷ yếu công trình nghiên cứu khoa học y học bjển.

6. Nguyê̂n Văn Tâm, Trân Thị Quỳnh Chi, Nguyễn Quang Hùng (2021). Thực trạng công tác chăm sóc sức khỏe cho ngư dân làm viếc trên tàu bắt hải sản tại một số ngư trường Vịnh Bắc Bộ, duyên hải miền Trung, Vịnh Thái Lan từ năm 2015-2017.s1.: tập 31, số 12021

7. C. Matheson, S. Morrison, et al (2001). The health of fishermen in the catching sector of the fishing industry: a gap analysis. s.l. : Occupational Medicine. 51(5), p. 305-311.

8. Olaf C. C. Jensen, Gudrun Petursdottir, et al (2014). A review of fatal accident incidence rate trends in fishing. s.l. : International maritime health. $65(2)$, p. 47-52.

\title{
KẾT QUẢ PHẪU THUÂ̂T NộI SOI LÔNG NGỰC ĐIỀU TRI TRÀN KHÍ MÀNG PHỔI TỰ PHÁT TIÊN PHÁT TẠI BỆNH VIỆN HỮU NGHI VIỆT ĐỨC
}

\author{
Nguyễn Đức Thái ${ }^{1}$, Phạm Hữu Lư $^{2}$, Trần Bình Giang ${ }^{2}$
}

\section{TÓM TẮT}

Đăt vấn đề: Tràn khí màng phổi tự phát tiên phát là bệnh lý thường xảy ra ở người trẻ với tỉ lệ tái phát nhất định. Hiện nay, phẫu thuật nội soi lổng ngực được sử dụng trong điêu trị tràn khí màng phổi tự phát tiên phát thướng quy tại các trung tâm phấu thuật lồng ngực. Phương pháp: Nghiên cứu mô tả cắt ngang; Kết quả nghiên cứu ghi nhận ở các biến số: Tuổi, giới tính; Thời gian phâ̂u thuật; Tỷ lệ gây dính màng phổi ; Thời gian hậu phẫu... Số liệu được ghi nhận vào mấu bệnh án nghiên cứu cho từng bệnh nhân và xử lý bằng chương trình SPSS 20.0. Kết quả: Từ tháng 01/2018 đến 04/2021 có 38 bệnh nhân được phẫu thuật nội soi lồng ngực điều trị tràn khí màng phổi tự phát tiên phát. Cắt đốt hoặc/và khâu bóng khí bằng Stapler hoặc khâu tay kèm có/không gây dính màng phổi bằng trà nhám màng phổi vùng đỉnh và gây dính chủ động bằng Betadin đặc. Thời gian phẫu thuật trung bình là 63,16 phút. Ngày nằm hậu phẫu trung bình 5,16 ngày. Không có biến chứng cững như tử vong. Theo dõi từ 1 tháng đến 24 tháng, không có trường hợp nào tái phát. Kết luận: Phẫu thuật nội soi lồng ngực là phương pháp ngoại khoa hiệu quả trong điều trị tràn khí màng phổi tự phát tiên phát với ưu

\footnotetext{
${ }^{1}$ Bệnh viện Phổi Hà Nội

${ }^{2}$ Bệnh viện Hữu nghi Việt Đức

Chịu trách nhiệm chính: Phạm Hữu Lư

Email: phamhuulu@hmu.edu.vn

Ngày nhận bài: 11.5.2021

Ngày phản biện khoa học: 28.6.2021

Ngày duyệt bài: 7.7.2021
}

điểm giảm đau sau mổ, giảm thời gian nằm viện và giảm tî lệ tái phát.

\section{SUMMARY \\ RESULTS OF VIDEO-ASSISTED \\ THORACOSCOPIC SURGERY FOR THE TREATMENT OF SPONTANEOUS PRIMARY SPONTANEOUS PREUMOTHORAX AT VIET DUC UNIVERSITY HOSPITAL}

Background: Primary spontaneous pneumothorax is a common disease in young people with a recurrence rate. Currently, video-assisted thoracoscopic surgery is used in the routine treatment of primary spontaneous pneumothorax in thoracic surgery centers. Methods: Cross-sectional descriptive study; The research results were recorded in the following variables: age, sex; operative time; rate of pleural adhesions; post-operative time... The data were recorded in the research medical record for each patient and processed by the SPSS 20.0. Results: From January 2018 to April 2021, 38 patients underwent video-assisted thoracoscopic surgery for primary spontaneous pneumothorax. Bleb ablation and/and blebectomy - suture with Stapler or manual suturing with/without pleural adhesions with apical pleural sanding and active adhesion with the pure Betadin. The average operative time was 63.16 minutes. The average postoperative day was 5.16 days. There were no complications nor death. Followup from 1 month to 24 months, no cases of recurrence. Conclusion: Thoracoscopic surgery is an effective surgical method in the treatment of primary spontaneous pneumothorax with the advantages of 